\title{
Effectiveness of Commercial versus Homemade Sports Drinks on Fluid Balance and Exercise Capacity during High-intensity Intermittent Exercise
}

\author{
Gulshanara Begum $^{1}$, Maria Konstantaki ${ }^{2, *}$, Adam Cunliffe ${ }^{3}$, Michael Leveritt ${ }^{4}$ \\ ${ }^{1}$ Department of Life Sciences, University of Westminster, London, United Kingdom \\ ${ }^{2}$ Department of Sports Management, Buckinghamshire New University, High Wycombe, United Kingdom \\ ${ }^{3}$ Department of Applied Science, London South Bank University, London, United Kingdom \\ ${ }^{4}$ School of Human Movement Studies, The University of Queensland, Australia \\ *Corresponding author: mkonst01@bucks.ac.uk
}

Received February 25, 2015; Revised March 26, 2015; Accepted May 08, 2015

\begin{abstract}
Commercial sports drinks are used widely by athletes involved in high-intensity intermittent (HII) exercise. However, little has been reported on their relative effectiveness compared to simple homemade drink formulations. The purpose of this study was to investigate the effects of different sports drink formulations (commercial v homemade), water and no drink on fluid balance and exercise capacity during HII exercise. Twelve trained men (age: $27 \pm 2.1 \mathrm{y}$ ) performed a 90-min HII running protocol designed to simulate activity experienced during a football match. The protocol was arranged in six 15-min stages where running speeds ranged between $55 \%$ and $120 \%$ of $\mathrm{VO}_{2 \max }$. The HII protocol included half-time and a run to fatigue post $90 \mathrm{~min}$. Using a single-blind, randomized, cross-over design, participants ingested a preload of $5 \mathrm{ml} \cdot \mathrm{kg}^{-1} 10 \mathrm{~min}$ before HII exercise and $3 \mathrm{ml} \cdot \mathrm{kg}^{-1}$ every 15 min of either Isostar ${ }^{\circledR}$ (ISO), a homemade sports drink (CHO), placebo (P) or no drink (ND). Blood lactate (Hla), blood glucose ( $\mathrm{B}_{\text {gluc }}$ ), heart rate (HR) and ratings of perceived exertion (RPE) were measured before, during (every $15 \mathrm{~min}$ ) and after the 90-min HII protocol. Changes in plasma volume were measured at half-time and post $90 \mathrm{~min}$. Sweat rate and fluid balance were calculated post each trial. Time to fatigue (TTF) was recorded at exhaustion. In the ND trial, TTF decreased by approximately $17 \%$, 28\% and $43 \%$ compared to P, CHO and ISO, respectively $(\mathrm{p}<0.01)$ and HR was highest at 90 min following ND trial $(\mathrm{p}<0.05)$. TTF was $20 \%$ longer in the ISO trial compared to $\mathrm{CHO}$, but this difference was not statistically significant ( $p>0.05$ ). No differences were noted in HLa, RPE, PV or SR between the trials ( $>00.05)$ but there were significant effects of time $(\mathrm{p}<0.05)$. $\mathrm{B}_{\text {gluc }}$ peaked at 30 minutes in ISO and CHO, but dropped by 27\% in ISO and by 30\% in CHO after half time. Absence of fluid ingestion surprisingly had no significant effect on altering plasma volume or decreasing sweat rate despite causing noticeable decreases in exercise capacity. The homemade drink improved exercise capacity in a similar manner to that of the commercial drink, but neither sports drink achieved superior hydration compared to water. Ingestion of exogenous carbohydrate through sports drink consumption caused an exercise-induced glycemic response when exercise was restarted after half-time. This decline in blood glucose after half-time appears to be marginally attenuated in P trial. A possible suggestion for team sports could be to drink water rather than sports drink prior to half-time period.
\end{abstract}

Keywords: advanced $v$ basic formulation sports drinks, exercise capacity, hydration status, high-intensity intermittent exercise

Cite This Article: Gulshanara Begum, Maria Konstantaki, Adam Cunliffe, and Michael Leveritt, "Effectiveness of Commercial versus Homemade Sports Drinks on Fluid Balance and Exercise Capacity during High-intensity Intermittent Exercise.” American Journal of Sports Science and Medicine, vol. 3, no. 2 (2015): 3946. doi: 10.12691/ajssm-3-2-3.

\section{Introduction}

Much has been written about the physiological effects of ingesting sports drinks during prolonged exercise. Sports drinks provide exogenous carbohydrate that is quickly absorbed by the gastrointestinal tract and acts to maintain optimal blood glucose levels, preventing hypoglycaemia while sparing endogenous carbohydrate stores [1]. Sports drinks also act to replace fluid and electrolytes lost during sweating and hence prevent dehydration and early onset of fatigue [2]. Previous studies have used mostly commercial sports drinks and have demonstrated improvements in endurance capacity during intermittent, moderate intensity exercise [3], moderate intensity exercise in the heat [4] and high intensity exercise protocols [5]. However, at present there 
are few published investigations available that have compared the differences or similarities of commercial versus basic sports drink formulations on exercise capacity during high intensity intermittent (HII) exercise lasting more than one hour.

The rationale for investigating the effectiveness of commercial versus basic sports drink formulations is based on evidence that regular consumption of commercial sports drinks may pose a risk to athletes' health [6]. First, commercial sports drinks such as Powerade, Gatorade, Isostar and Lucozade are designed using hypertonic formulations i.e. the drink contains higher amounts of sodium chloride than the body's cells (osmolality 280-350 mosmol $\cdot \mathrm{kg}^{-1}$ ) which can delay gastric emptying and water absorption from the proximal small intestine and hence may promote the occurrence of exercise-related abdominal pain in susceptible individuals [7]. Second, commercial sports drink formulations are known for their high acidity levels (pH: 2.4-4.5) which has been linked to dental erosion if large volumes are consumed over time [6]. Third, commercial drinks contain numerous non-traditional ingredients such as preservatives, colourings, artificial sweeteners and flavours that are used to improve palatability and prolong self life [2]. There is evidence to suggest that artificial colourings and preservatives in food and drink boost levels of hyperactivity in pre-school children [8]. These health risks may be negligible if sports drink consumption is low, however it has been reported that elite athletes may consume up to $1 \mathrm{~L}$ of commercial sports drinks per day [7]. Conversely, it has been suggested that sports drinks with neutral pH and hypotonic formulations (osmolality 200250 mosmol $\cdot \mathrm{kg}^{-1}$ ) can be easily prepared with low osmolality fruit juice (apple or tomato) diluted with water and a pinch of salt to be used by athletes during training and competition [2]. Indeed, there is evidence that suggests that commercial $\mathrm{CHO}$ feedings do not confer extra benefits to performance compared to natural $\mathrm{CHO}$ alternatives. Earnest et al. [9] demonstrated that supplementation with a commercial CHO gel (dextrose) was as effective as a natural form of CHO gel (honey) in improving cycling time trial performance over $64 \mathrm{~km}$ compared to placebo. While commercial energy drinks are convenient, they are also expensive. As long as athletes hydrate well during exercise alongside ingesting recommended nutrients (e.g., $\mathrm{CHO}$, a pinch of salt and some potassium), it may be possible to achieve similar results more affordably and without risking health hazards. However, there is limited information available on the relative effectiveness of homemade versus commercial energy drinks on physiological or performance measures.

Another research issue is the hydration ability of sports drinks versus water. Sports drinks in general have been shown to be more effective in improving endurance performance compared to water [4], which has been attributed to quick oxidation of exogenous carbohydrate (rate of $1 \mathrm{~g} / \mathrm{min}$ ) that provides energy during continuous exercise [10] while maintaining electrolyte balance [11]. The American College of Sports Medicine (ACSM) recommends that, to sustain high intensity exercise events of $\sim 1 \mathrm{~h}$ or longer or less intense events lasting for longer periods, endurance athletes should ingest one-half to one litre of a conventional sports drink (assuming 6-8\% carbohydrate i.e. 6-8 grams per $100 \mathrm{ml}$ of fluid which would provide $30-80 \mathrm{~g} \cdot \mathrm{h}^{-1}$ of carbohydrate) along with sufficient water to avoid excessive dehydration [12]. However, ingestion of a sports drink will not delay fatigue during exercise lasting less than $1 \mathrm{hr}$ or during an intense bout of exercise lasting 20-30 min [13]. Similarly, in conditions of dehydration-induced hyperthermia during exercise lasting 1-3 h [14] sports drink consumption is not affective. It appears that under such conditions, maintaining hydration is the body's priority. The International Society of Sport Nutrition (ISSN) recommends that athletes need to ingest $0.5-2.0 \mathrm{~L} \cdot \mathrm{h}^{-1}$ of fluid i.e. 6-8 ounces or 1 cup of cold water or sports drink every 5-15 min (depending on temperature, humidity, exercise intensity and the athlete's sweat response to exercise) to maintain fluid balance and prevent dehydration [15]. It has been noted that commercial sports drinks have similar hydration ability to water [16]. Previous studies that have examined fluid balance or assessed sweat rates investigated the effect of water versus sports drink consumption during exercise in the heat of tennis [17] and soccer players [18]. To the knowledge of the investigators, there have been no published studies which have compared the hydration ability of different formulation sports drinks against water and no drink. Therefore, the purpose of this study was to compare the effectiveness of a commercial versus a homemade sports drink against water and no drink on fluid balance and exercise capacity during HII exercise.

\section{Methods}

\subsection{Participants}

Twelve trained males (age: $27 \pm 2.1 \mathrm{y}$, stature: $182 \pm$ $0.2 \mathrm{~cm}$, body mass: $78 \pm 3.3 \mathrm{~kg}, \mathrm{VO}_{2 \max : ~} 52.5 \pm 1.7 \mathrm{ml} \cdot \mathrm{kg}^{-}$ $\left.{ }^{1} \cdot \mathrm{min}^{-1}\right)$, provided written informed consent and participated in the study. The study received ethical approval by the Ethics Committee of the British College of Osteopathic Medicine. None of the participants suffered from recent injuries or medical conditions that might alter their physiological response to exercise testing. Participants were instructed to refrain from strenuous training, alcohol and caffeine consumption for $24 \mathrm{~h}$ prior to each trial session. To standardise nutritional intake, participants kept a food diary the day before their first trial session and were then instructed to consume the same diet for $24 \mathrm{~h}$ prior to subsequent trial sessions.

\subsection{Experimental Design}

All tests were carried out on a motorised treadmill (HP Cosmos ${ }^{\circledR}$, Germany). The study included five sessions; one preliminary and four drink trial sessions. The drink trial sessions were performed in a randomised order to offset any training effects. Each trial was separated from the next by at least $7 \mathrm{~d}$. Experimentation was conducted using a cross-over, single-blind study design where only the experimenter was aware of the drink type. Participants were blinded to drink type and drinks were delivered in opaque bottles to mask visual information. Participants also wore nose clips during drink consumption to minimise any olfactory or gustatory information. 


\subsection{Preliminary Measurements}

During the preliminary visit, participants' peak oxygen uptake $\left(\mathrm{VO}_{2 \max }\right)$ was estimated by means of a progressive incremental test (using 1-min stages) to volitional fatigue. This test was a modified version of the original cycling protocol described by Roffey et al. [19]. Oxygen uptake was measured using an online gas analysis system (Oxycon Delta, Jaeger, Hoechberg, Germany). Running speeds corresponding to $55 \%, 95 \%$ and $120 \%$ of $\mathrm{VO}_{2 \max }$ were calculated for each participant from this preliminary test. Participants then performed $15 \mathrm{~min}$ of the high intensity intermittent (HII) running protocol to familiarize themselves.

\subsection{HII Exercise Protocol}

The 90-min HII treadmill running protocol was a modified version of the intermittent protocols previously used by Welsh et al. [20] and Nicholas et al. [21]. The test was performed at 1\% gradient as Jones and Doust [22] found that lack of air resistance when running indoors on a treadmill can result in lower energy cost compared with running outdoors at the same velocity. They demonstrated that a $1 \%$ treadmill gradient represents equal energetic cost as outdoor running. The protocol was divided into two 45 min periods each comprising three 15-min running bouts. Each 15-min bout involved sequences which consisted of $40 \mathrm{~m}$ moderate paced walking, $40 \mathrm{~m}$ sprint at $120 \% \mathrm{VO}_{2 \max }, 60 \mathrm{~m}$ slow jog at $55 \% \mathrm{VO}_{2 \max }$ and $60 \mathrm{~m}$ fast jog at $95 \% \mathrm{VO}_{2 \max }$. After $45 \mathrm{~min}$, a half-time period was given ( 15 $\mathrm{min}$ ) and after $90 \mathrm{~min}$ another recovery period was given before subjects completed the run to fatigue task. The run to fatigue consisted of repeated $20 \mathrm{~m}$ intervals at sprint speed $\left(120 \% \mathrm{VO}_{2 \max }\right)$ and slow jog speed $\left(55 \% \mathrm{VO}_{2 \max }\right)$ until volitional fatigue.

\subsection{Experimental Drink Trials}

On the morning of a trial, participants visited the laboratory after a 10-12 hr fast and voided their bladders before the measurement of body mass and baseline blood chemistry measurements. Participants then consumed either no drink or a drink pre-load (ISO, CHO or P) equal to $5 \mathrm{ml} \cdot \mathrm{kg}^{-1}$ of body mass $10 \mathrm{~min}$ before the start of exercise to allow time for gastric emptying [12]. After the 10-min period allowed for drink absorption, participants performed a 10-min warm-up (i.e. jogging, stretching and striding). Participants then began the HII running protocol and consumed either no drink or $3 \mathrm{ml} \cdot \mathrm{kg}^{-1}$ of drink at the start of each $15 \mathrm{~min}$ which is in accordance to international sports nutrition recommendations [15,23]. Blood samples, physiological and psychological measurements were taken during the 3-min standing rest periods that followed each 15-min exercise bout.

\subsection{Drink Formulations}

Drink conditions included consumption of a commercial drink (ISO), a homemade drink (CHO), a placebo drink (P) and no drink (ND). ISO was Isostar ${ }^{\circledR}$ with activator-complex containing 6.8\% carbohydrate and $0.069 \mathrm{~g}$ sodium $/ 100 \mathrm{ml}$. Whilst potassium, plus a number of other ingredients were contained in Isostar ${ }^{\circledR}$, details regarding precise amounts were not available on label. The homemade CHO drink took an average of the concentration of carbohydrate, sodium and potassium in popular commercial drinks (Lucozade, Gatorade and Isostar) and consisted of $6.3 \%$ carbohydrate, $0.06 \mathrm{~g}$ sodium $/ 100 \mathrm{ml}$ and $0.01 \mathrm{~g}$ potassium $/ 100 \mathrm{ml}$. The homemade drink was flavoured using zero calorie fruit flavouring $\left(\mathrm{CHO}<0.15 \mathrm{~g} \cdot \mathrm{L}^{-1}\right)$. The carbohydrate content of the commercial and homemade drink was within the ACSM/ADA/Dieticians of Canada (2009) recommendations for carbohydrate supplementation during exercise (approximately 30-60 $\mathrm{g} \cdot \mathrm{h}^{-1}$ ) for maintenance of blood glucose levels [24]. P was energy and electrolyte-free drink prepared with water and zero calorie fruit flavouring.

\subsection{Blood, Physiological and Psychological Measurements}

Blood samples were taken every $15 \mathrm{~min}$ and were analysed for blood glucose $\left(B_{\text {gluc; }} \mathrm{mmol} \cdot \mathrm{L}^{-1}\right)$ using a portable blood glucose analyser (Accutrend, Roche Diagnostics, Mannheim, Germany) and blood lactate concentration ( $\mathrm{HLa}$; $\mathrm{mmol} \cdot \mathrm{L}^{-1}$ ) using a portable blood lactate analyser (Accusport, Boehringer Mannheim Co, Indianapolis). Haemoglobin (Hb) and Haematocrit concentrations were determined at rest, during half-time and following exercise using a mini-photometer (Dr Lange LP20, Germany). Changes in plasma volume were then calculated from $\mathrm{Hb}$ and Hct readings according to the method described by Dill and Costill [25].

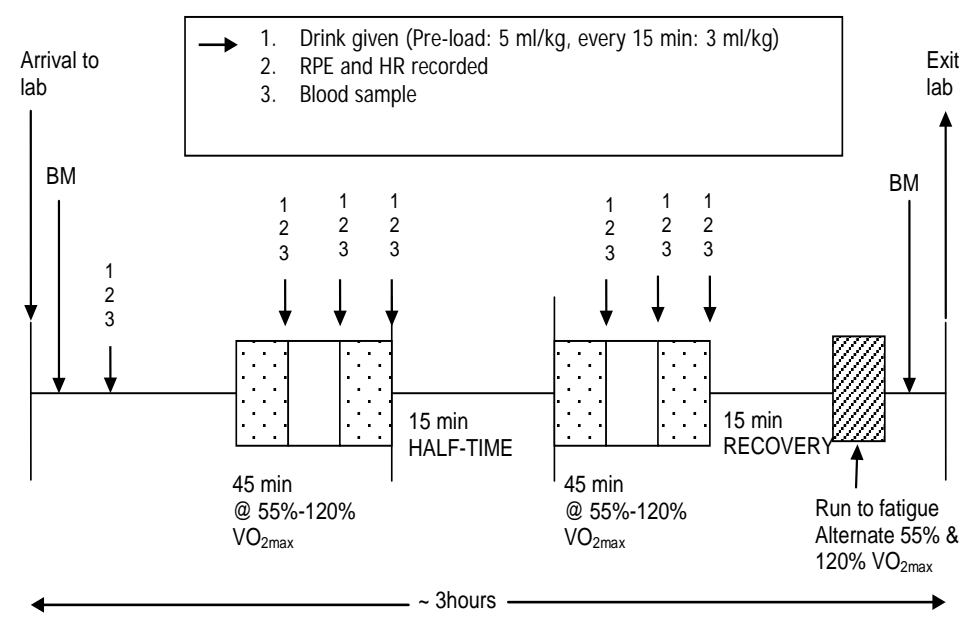

Figure 1. The study protocol showing the timing of drink ingestion and measurements 
Heart rate (HR; b· $\left.\mathrm{min}^{-1}\right)$ was recorded using a telemetric system (Polar $1610^{\mathrm{TM}}$, Kempele, Finland) every 15 min. Ratings of perceived exertion (RPE; 6-20 scale) were recorded every $15 \mathrm{~min}$. Body mass $(\mathrm{kg})$ was measured before and after each trial session and the change was recorded in grams (g). A schematic of the exercise protocol and timing of measurements can be seen in Figure 1.

Fluid intake and toilet losses during the drink trials were recorded in $\mathrm{g}$ and converted to $\mathrm{ml}(1 \mathrm{~g}=1 \mathrm{ml})$. No correction was made for respiratory water losses or metabolic fluid changes [26]. Fluid balance and sweat rate were estimated as follows:

Net water loss (g)

=Change in body mass $(\mathrm{g})+$ Fluid intake $(\mathrm{g})$

- Toilet losses (g)

Sweat rate $\left(\mathrm{L} \times \mathrm{h}^{-1}\right)$

$=$ Net water loss $(\mathrm{L}) /$ exercise time $(\mathrm{h})$

Fluid balance $(\mathrm{ml})$

$=$ Fluid intake $(\mathrm{ml})-$ Sweat loss $(\mathrm{ml})$

\subsection{Statistical Analysis}

Statistical analysis was performed using SPSS (v16.0; SPSS, USA). Data are reported as mean \pm SEM. Data was analysed using one-way ANOVAs and repeated measures ANOVAs with planned contrasts. Specific differences were determined using Bonferroni post-hoc tests. The level of significance was accepted at $\mathrm{p}<0.05$.

\section{Results}

Ambient temperature (ND: $21.7 \pm 0.56{ }^{\circ} \mathrm{C}, \mathrm{P}: 21.4 \pm$ $0.39{ }^{\circ} \mathrm{C}$, CHO: $21.5 \pm 0.54{ }^{\circ} \mathrm{C}$, ISO: $\left.21.5 \pm 0.43{ }^{\circ} \mathrm{C}\right)$, barometric pressure (ND: $760 \pm 1 \mathrm{mmHg}, \mathrm{P}: 761 \pm 1$ mmHg, CHO: $761 \pm 2 \mathrm{mmHg}$, ISO: $760 \pm 2 \mathrm{mmHg}$ ) and relative humidity (ND: $34.25 \pm 2.20 \%$, P: $38.33 \pm 2.51 \%$, CHO: $37.83 \pm 2.82 \%$, ISO: $38.5 \pm 2.63 \%$ ) were similar between trials $(p>0.05)$. HR was highest at $90 \mathrm{~min}$ of exercise during the ND trial $\left(179 \pm 3.6 \mathrm{~b} \cdot \mathrm{min}^{-1}\right)$ compared to $\mathrm{P}\left(171 \pm 2.8 \mathrm{~b} \cdot \mathrm{min}^{-1}\right)$, CHO $\left(171 \pm 3.2 \mathrm{~b} \cdot \mathrm{min}^{-1}\right)$ and ISO $\left(170 \pm 4.1 \mathrm{~b} \cdot \mathrm{min}^{-1} ; \mathrm{p}<0.05\right)$. There were no significant differences in HR between the drink conditions ( $>>0.05)$. Coefficients of variation (CV) ranged from $1.63 \%$ to $2.41 \%$. Ingestion of drink decreased RPE with ISO trial producing slightly lower values at 45 and $90 \mathrm{~min}$. However, despite these trends, no significant differences were found between the trials ( $p>0.05$ ).

The amount of fluid ingested during the drink trials was similar with no significant differences detected (P: $1546 \pm$ $64 \mathrm{ml}$, CHO: $1541 \pm 62 \mathrm{ml}$, ISO: $1548 \pm 61$; p>0.05). Sweat rate did not differ between the four drink conditions (ND: $1.5 \pm 0.11 \mathrm{~L} \cdot \mathrm{h}^{-1}$, P: $1.6 \pm 0.09 \mathrm{~L} \cdot \mathrm{h}^{-1}$, CHO: $1.5 \pm 0.10$ $\mathrm{L} \cdot \mathrm{h}^{-1}$, ISO: $\left.1.5 \pm 0.11 \mathrm{~L} \cdot \mathrm{h}^{-1} ; \mathrm{p}>0.05\right)$. Total body water loss was significantly lower in the ND trial $(2.9 \pm 0.17 \%$; $\mathrm{p}<0.05)$ compared to the $\mathrm{P}(3.5 \pm 0.10 \%)$, CHO $(3.4 \pm$ $0.11 \%$ ) and ISO trials (3.2 $\pm 0.14 \%$ ), however it did not differ between the $\mathrm{P}, \mathrm{CHO}$ and ISO trials $(\mathrm{p}>0.05)$. The $\mathrm{CV}$ ranged between $2.85 \%$ to $5.0 \%$. These results are shown in Figure 2.

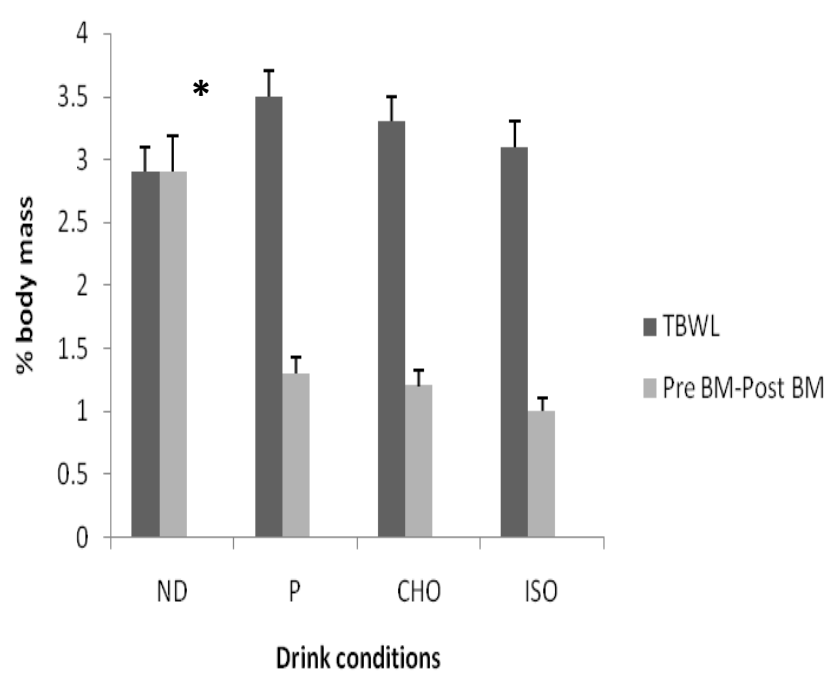

Figure 2. Changes in body mass (pre BM-post BM) and total body water loss (TBWL) before and after the 90 min protocol represented as a \% of body mass at baseline. * Significant difference in TBWL between ND and $\mathrm{P}, \mathrm{CHO}$, ISO

Fluid balance was shown to be negative in all drink conditions by approximately $0.5 \mathrm{~L} \cdot \mathrm{h}^{-1}$ but did not differ significantly between the drink trials $(p>0.05)$. Fluid balance was significantly more negative in the ND trial ($\left.1.49 \pm 0.11 \mathrm{~L} \cdot \mathrm{h}^{-1}\right)$ compared to $\mathrm{P}\left(-0.59 \pm 0.66 \mathrm{~L} \cdot \mathrm{h}^{-1}\right)$, CHO $\left(-0.53 \pm 0.77 \mathrm{~L}^{-1} \mathrm{~h}^{-1}\right)$ and ISO $\left(-0.52 \pm 0.76 \mathrm{~L} \cdot \mathrm{h}^{-1}\right)$ at $\mathrm{p}<0.05$.

Blood plasma volume decreased after 45 min compared to baseline by $7.8 \pm 1.9 \%$ in ND, $6.3 \pm 1.2 \%$ in $\mathrm{P}, 9.7 \pm$ $1.3 \%$ in $\mathrm{CHO}$ and $7.3 \pm 0.8 \%$ in ISO and remained at similar levels at $90 \mathrm{~min}$. There were no differences between the drink trials $(\mathrm{p}>0.05)$. However, there was a trend for plasma volume to decrease further in the ND trial $(7.8 \pm 1.9$ at $45 \mathrm{~min}$ versus $8.7 \pm 1.2 \%$ at $90 \mathrm{~min})$, while the other trials showed some recovery at 90-min compared to 45 min but this difference was not significant $(\mathrm{p}<0.05)$. There was an affect of time regardless of drink condition $(\mathrm{p}<0.001)$. CV ranged from $10.3 \%$ to $24 \%$. These results are shown in Figure 3.

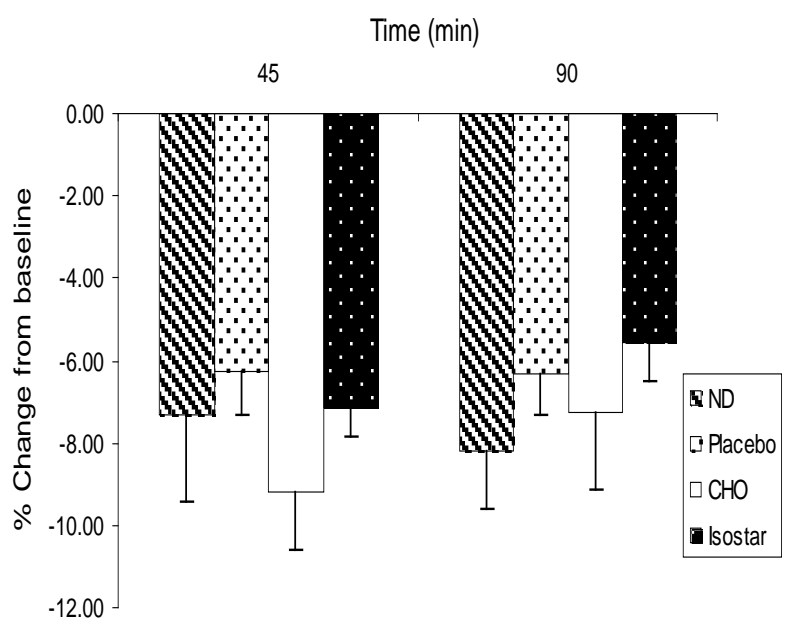

Figure 3. Changes in plasma volume for the different drink conditions at 45 and 90 min of the HII running protocol

HLa (mmol $\left.\cdot \mathrm{L}^{-1}\right)$ remained above baseline at all sampling points for all drink conditions $(\mathrm{p}<0.001)$. Whilst $\mathrm{HLa}$ appeared to be lower in the CHO trial, the difference was not significant between the other conditions at 
completion of the exercise test. There was a slight reduction in $\mathrm{HLa}$ concentration following half-time in all drink conditions, but this was not significant ( $p>0.05)$.

$\mathrm{B}_{\text {gluc }}$ was elevated throughout the protocol for all trials. During the ISO and $\mathrm{CHO}$ trial, $\mathrm{B}_{\text {gluc }}$ was consistently higher compared to $\mathrm{P}$ and ND at 15, 45, 75 and 90 min of exercise. $\mathrm{B}_{\text {gluc }}$ peaked at 30 min during exercise, but then reduced following half-time (i.e. between $45 \mathrm{~min}$ and 60 min of the exercise protocol). The reductions in $\mathrm{B}_{\text {gluc }}$ after half-time were: $16 \%$ in ND, $14.5 \%$ in P, $30 \%$ in CHO and $26.5 \%$ in ISO. Bonferroni post-hoc analysis showed a significant difference in $\mathrm{B}_{\text {gluc }}$ levels for $\mathrm{P}$ versus $\mathrm{CHO}$ $(\mathrm{p}<0.05)$, P versus ISO $(\mathrm{p}<0.05)$, ND versus $\mathrm{CHO}(\mathrm{p}<0.05)$ and ND versus ISO $(\mathrm{p}<0.05)$. There was no significant difference in $\mathrm{B}_{\text {gluc }}$ response between $\mathrm{CHO}$ and ISO at any time point $(\mathrm{p}>0.05)$. These results are shown in Figure 4.

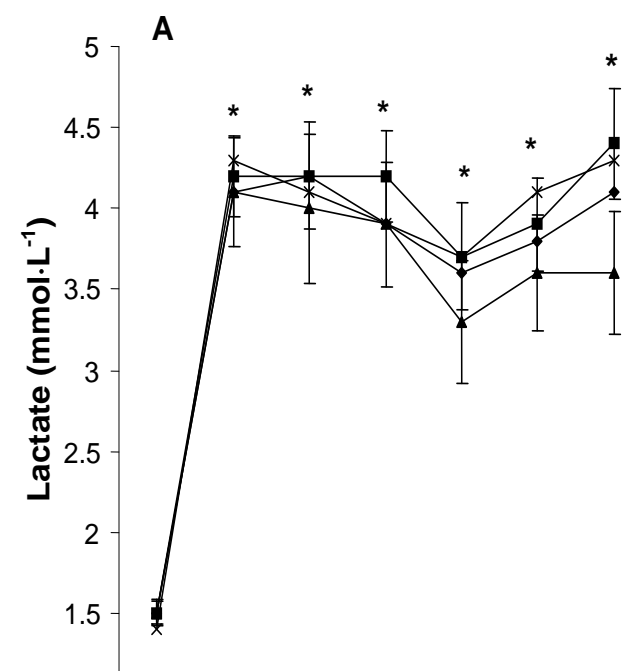

B

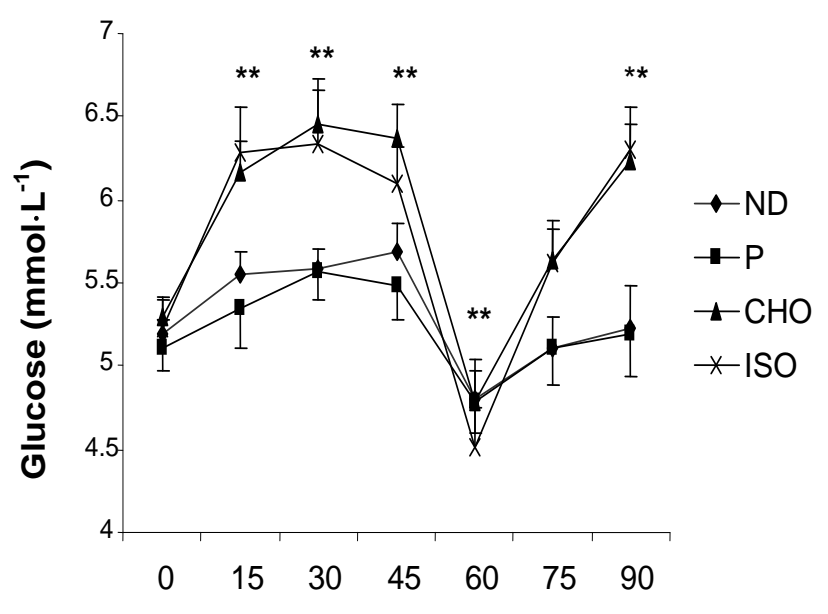

Figure 4. Blood lactate $(\mathrm{A})$ and blood glucose $(\mathrm{B})\left(\mathrm{mmol} \cdot \mathrm{L}^{-1}\right)$ responses during the intermittent treadmill protocol. * represents significant difference in lactate readings between baseline and time points $(\mathrm{p}<0.001)$ and $* *$ represents significant difference in glucose readings between baseline and time points for CHO and ISO v P and ND $(\mathrm{p}<0.001)$

Time to fatigue was significantly shorter in the ND trial (134.4 $\pm 16.2 \mathrm{~s})$ compared to P $(161.4 \pm 18.3 \mathrm{~s})$ but this $17 \%$ difference was not significantly different $(\mathrm{p}>0.05)$. Planned contrasts showed a significant 28\% difference between ND trial v CHO trial (187.8 \pm 15.2 s) and a $43 \%$ difference between ND v ISO (234.6 $\pm 34.1 \mathrm{~s}, \mathrm{p}<0.05)$. Post-hoc analysis revealed that there was also significant difference between $\mathrm{P}$ and ISO trial $(\mathrm{p}<0.05)$. Although run time to fatigue for ISO was approximately $20 \%$ longer compared to $\mathrm{CHO}$ this difference was not statistically significant $(\mathrm{p}>0.05)$. CV ranged from $8.09 \%$ to $14.5 \%$. These results are shown in Figure 5.

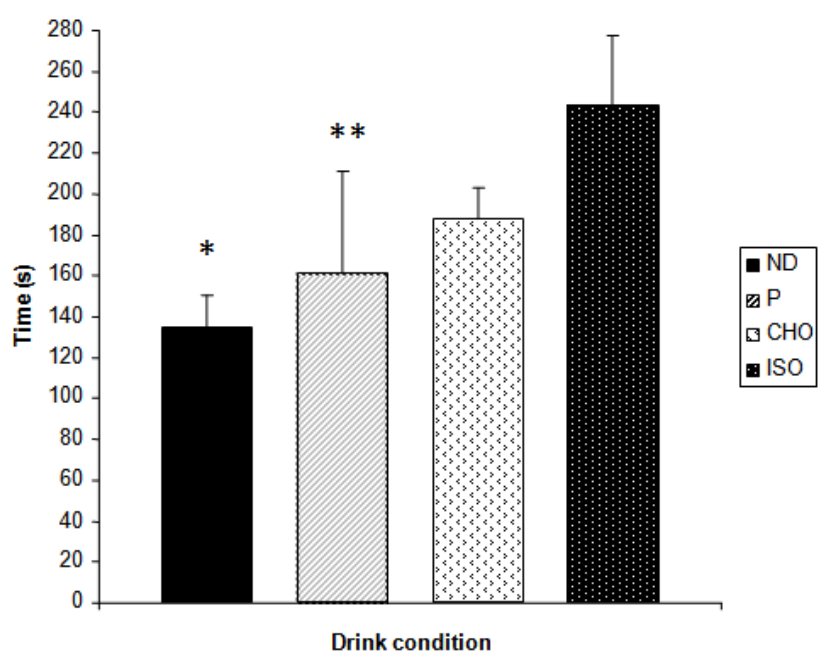

Figure 5. Run times to fatigue for the drink conditions. * represents significant difference between ND versus CHO and ISO $(\mathrm{p}<0.05)$ and ** represents significant difference between $\mathrm{P}$ and ISO $(\mathrm{p}<0.05)$

\section{Discussion}

Commercial sports drinks are widely used by athletes involved in HII exercise. However, there is scarcity of studies investigating their relative effectiveness compared to simple homemade drink formulations. The current study found that time to fatigue was significantly shorter in the ND trial compared to $\mathrm{P}$ (17\% longer), and even more so compared to CHO (28\% longer) and ISO (43\% longer). These findings indicate that absence of drink ingestion may increase the rate of carbohydrate oxidation, accelerating depletion of endogenous carbohydrate and possibly causing earlier onset of fatigue [27]. However, carbohydrate oxidation was not measured in this study. Nevertheless, it appears that when fluid was ingested, it had a 'glycogen sparing' effect [28] that was maximised with ingestion of exogenous carbohydrate $[10,28]$ through a sports drink. Nicholas et al. [5] reported a 33\% improvement in exercise capacity during $75 \mathrm{~min}$ of intermittent high intensity running following ingestion of a sports drink compared to placebo. Other studies have also shown improvements in cycling time trial performance with a $6.4 \%$ sports drink compared to placebo [29] and in exercise capacity following ingestion of a $6.0 \%$ sports drink [30].

Time to fatigue did not differ between the commercial and homemade sports drink. ISO produced approximately $20 \%$ longer run times to fatigue, however this effect was not significant. In addition, it was not supported by differences in blood glucose or lactate levels that might indicate faster glycogen depletion or metabolic acidosis in the CHO trial [31]. This finding agrees with those previously reported by Coombes and Hamilton [29] who suggested that no given commercial sports drink is 
superior to other sports drinks. The current study was designed so that participants were required to consume identical amounts of drink (P, ISO or CHO) thus the effects of drink palatability [32] and ad libitum consumption could not have been the underlying mechanism for the differences observed. Even though the investigators attempted to mask the type of drink consumed by using a nose clip and opaque drinking bottles, it is possible that participants experienced a 'placebo effect' on performance during the ISO trial. This is particularly the case for those participants who may have recognised the flavour from prior sports drink use. However, the participants' perception of the type of drink consumed was not assessed.

Absence of fluid ingestion caused significant fluid deficit that resulted in thermal strain evident from increased heart rates towards the end of the protocol. This finding reflects the cardiovascular drift associated with dehydration during prolonged exercise [33]. In addition, an upward trend was observed for RPE which agrees with previous observations during high-intensity cycling to exhaustion and reflects capacity impairment that is associated with low levels of dehydration [34]. However in this study, no differences were observed in RPE between the trials. This contradicts the findings of Davis et al. [31] who observed lower RPE responses during a high intensity, intermittent protocol for a $6 \%$ sports drink compared to placebo. However, Davis et al. used prolonged cycling at $120-130 \% \mathrm{VO}_{2 \max }$ at 1 min intervals with untrained participants, which makes comparisons difficult.

Fluid balance was similar between the drink trials. A previous study that compared the hydration qualities of three commercial drinks against water also found no differences in their hydration ability [16]. In the current study, a positive fluid balance was not achieved following any of the drink trials according to the volume of drink consumed, even though the amounts consumed were higher by approximately $400 \mathrm{ml}$ compared to those reported previously for a similar duration high intensity intermittent protocol [5]. It appears that fluid intake failed to match body water loss and resulted in a fluid deficit. However, the time course of fluid absorption from the gut has been suggested to take at least $40 \mathrm{~min}$ [13] and even more so during HII exercise which has been shown to slow down gastric emptying [35]. Therefore, it might be the case that some of the fluid participants ingested towards the latter stages of the protocol still remained in the gut when plasma volume measurements were taken at the end of the exercise.

The ND trial caused an average $2.9 \%$ loss of body mass indicating dehydration. Even though the use of body mass to quantify hypohydration has been debated, it is still considered the only realistic measure of hypohydration available [36]. Previously, Coso et al. [4] reported a 3.7\% loss of body mass during 120 min of cycling without fluid ingestion, but the trial was performed in a hot environment $\left(36^{\circ} \mathrm{C}\right)$ which accelerated dehydration. In the current study, absence of fluid ingestion resulted in an average 29.3\% decrease in exercise capacity compared to the fluid trials. This is consistent with previous observations of exercise lasting more than $90 \mathrm{~min}$ in temperate environments of $20-21^{\circ} \mathrm{C}$ where more than $2 \%$ dehydration has been noted to impair performance [27]. The findings from the current study add to the body of literature that states fluid consumption is paramount during high intensity intermittent exercise of $90 \mathrm{~min}$. Its primary aim is to prevent dehydration [2] and hence concomitant decreases in exercise capacity. Therefore, fluid consumption has obvious implications for sporting events of this duration.

Plasma volume decreased after $45 \mathrm{~min}$ (range depending on drink condition: 6.3\% to 9.7\%) and remained at similar levels at 90 min of exercise with some recovery observed in the drink trials. Previously, Costill and Fink [37] observed that, following an initial reduction, plasma volume recovers around half of the volume lost within the first 30 min of exercise. After this point, plasma volume remains relatively stable during exercise lasting two hours at $9 \%$ less than the prehydration volume. Even in the ND condition, changes in plasma volume were similar to the changes seen in the fluid trials. This finding highlights the body's ability to regulate plasma volume according to circulatory demands imposed by exercise [37]. Alternatively, it may have been that fluid replacement did not influence plasma volume because the participants in this study begun exercising in a euhydrated state. Only minor dehydration is experienced in such condition [28].

Blood glucose concentration was shown to be significantly higher during the $\mathrm{CHO}$ and ISO trial compared to the ND and P trial throughout the protocol. This finding stands as evidence that a homemade sports drink produces similar blood glucose levels following ingestion to those produced by a commercial sports drink. It was also observed that blood glucose decreased markedly by $27 \%$ in the ISO trial and by $30 \%$ in the $\mathrm{CHO}$ trial between 45 and 60 min i.e. during half-time. This finding compares well with those stated by Russell et al., [38] who used a similar concentration sports drink (6\% sucrose-electrolyte drink) during a simulated soccer match and observed a decline in blood glucose levels following half time. Previously, it has been suggested that the reason for this decline could be rebound hypoglycemia [1]. However, in the current study, blood glucose concentrations were not below $3.5 \mathrm{mM}$ at $60 \mathrm{~min}$ to indicate that rebound hypoglycemia occurred. It appears that blood glucose concentrations fall as soon as exercise ceases, as glucose is no longer required. The exercise intensities used in the current study protocol did not result in hypoglycemia.

Finally, the decline in blood glucose at $60 \mathrm{~min}$ in the $\mathrm{P}$ trial was considerably lower than $\mathrm{CHO}$ and ISO and marginally lower than the ND trial. This finding might suggest that prior to half time, water rather than sports drink ingestion might be more appropriate in order to avoid the insulinemic response. However, more research is needed to verify this hypothesis and indeed, establish more effective carbohydrate-electrolyte drink ingestion strategies that aim to maintain optimum exercise capacity during HII exercise lasting more than one hour.

\section{Practical Implications}

A homemade drink containing 6.3\% carbohydrate and electrolytes enhances exercise capacity as much as a commercial sports drink during 90 min of high intensity intermittent running 
Ingestion of exogenous carbohydrate through a sports drink may not be advisable before half time as it brings about an exercise-induced glycaemic response when exercise is restarted after half time.

Absence of fluid ingestion may not alter sweat rate or plasma volume, but it causes dehydration and thermal strain that in turn negatively affect exercise capacity.

\section{Conclusions}

Exogenous carbohydrate supplementation using either a homemade or a commercial drink equally enhances exercise capacity and maintains hydration during HII running. The ND trial caused significant dehydration, thermal strain and reduced exercise capacity however plasma volume remained unaltered. Both the advanced and basic formulation (homemade) drinks had similar effects on performance, glucose homeostasis and lactate concentration. The plasma volume stabilising effect of either a homemade or a commercial sports drink is not different to that produced from drinking water. Therefore, an athlete can adapt the drink depending on the type of exercise, environmental conditions and personal tolerance

\section{Acknowledgements}

This study did not receive financial support from external agencies. The authors are grateful to Mrs Carol Seaward for her technical support and all the study participants who undertook the exercise tests.

\section{Conflict of Interest Statement}

None.

\section{References}

[1] Jeukendrup A.E, Killer, S.C. "The myths surrounding pre-exercise carbohydrate feeding," Annals of Nutrition and Metabolism, 57 (2), 18-25, 2010.

[2] Shirreffs, S. "The optimal sports drink," Schweizerische Zeitschrift für «Sportmedizin und Sporttraumatologie, 51, 25-29, 2003.

[3] Febbraio, M.A., Chiu, A., Angus, D.J, Arkinstall, M.J., Hawley, J.A. "Effects of carbohydrate ingestion before and during exercise on glucose kinetics and performance," Journal of Applied Physiology, 89, 2220-226, 2000a.

[4] Coso, J., Estevez, E., Baquero, R., Mora-Rodriguez, R. "Anaerobic performance when rehydrating with water or commercially available sports drinks during prolonged exercise in the heat," Applied Physiology, Nutrition and Metabolism, 33, 290298, 2008.

[5] Nicholas, C.W, Tsintzas, K., Boobis, L., Williams, C. "Carbohydrate-electrolyte ingestion during intermittent highintensity running," Medicine and Science in Sports and Exercise, 31(9), 1280-6, 1999.

[6] Coombes, J. "Review article: Sport drinks and dental," American Journal of Dentistry, 18, 101-04, 2005

[7] Mettler, S., Rusch, C., Colombani, P. "Osmolality and pH of sports and other drinks available in Switzerland," Schweizerische Zeitschrift für «Sportmedizin und Sporttraumatologie» 54, 92-95, 2006.

[8] Bateman, B., Warner, J.O., Hutchison, E., Dean, T., Rowlandson, P., Gant, C., Grundy, J., Fitzgerald, C., Stevenson, J. "The effects of a double blind, placebo controlled, artificial food colourings and benzoate preservative challenge on hyperactivity in a general population sample of preschool children," Archives of Disease in Childhood, 89, 506-511, 2004.

[9] Earnest, C.P., Lancaster, S.L., Rasmussen, C.J., Kerksick, C.M., Alejandro, A., Greenwood, M.C., Almada, A.L., Cowan, P.A., Kreider, R.B. "Low vs high carbohydrate gel ingestion during simulated $64 \mathrm{~km}$ cycling time trial performance," Journal of Strength and Conditioning Research, 18(3), 466-472, 2004.

[10] Convertino, V., Armstrong, L., Coyle, E., Mack, G.W., Sawka, M.N., Senay, L.C., Sherman, W.M. "American College of Sports Medicine position stand: exercise and fluid replacement," Medicine and Science in Sports and Exercise, 28, i-vii, 1996.

[11] Chryssanthopoulos, C., Williams, C., Nowitz, A. "Influence of a carbohydrate-electrolyte solution ingested during running on muscle glycogen utilisation in fed humans," International Journal of Sports Medicine, 23, 279-284, 2002.

[12] Sawka, M.N., Burke, L.M., Eichner, R., Maughan, R.J., Montain, S.J., Stachenfeld, N.S. "Exercise and fluid replacement," American College of Sports Medicine (ACSM) Position Stand, Medicine and Science in Sports and Exercise, 39(2), 377-390, 2007.

[13] Coyle, E.F. "Fluid and fuel intake during exercise," Journal of Sports Sciences, 22, 39-55, 2004.

[14] Fritzsche, R.G, Switzer, T.W, Hodgkinson, B.J, Lee, S-H., Martin, J.C., Coyle, E.F. "Water and carbohydrate ingestion during prolonged exercise increase maximal neuromuscular power," Journal of Applied Physiology, 88, 730-737, 2000.

[15] Kreider, R.B., Wilborn, C.D., Taylor, L., Campbell, B., Almada, A.L., Collins, R., Cooke, M., Earnest, C.P., Greenwood, M., Kalman, D.S., Kerksick, C.M., Kleiner, S.M., Leutholtz, B., Lopez, H., Lowery, L.M., Mendel, R., Smith, A., Spano, M., Wildman, R., Willoughby, D.S., Ziegenfuss, T.N., Antonio, J. "International Society of Sport Nutrition, exercise and sport nutrition review: research and recommendations," Journal of the International Society of Sports Nutrition, 7(7), 1-43, 2010.

[16] Hill, R., Bluck, L., Davies, P. "The hydration ability of three commercially available sports drinks and water," Journal of Science and Medicine in Sport, 11, 116-123, 2008.

[17] Bergeron, M., Waller, J., Marinik, E. "Voluntary fluid intake and core temperature responses in adolescent tennis players: sports beverage versus water," British Journal of Sports Medicine, 40, 406-410, 2006.

[18] DaSilva, R.P., Mundel, T., Natali, A.J., Bara Filho, M.G., Alfenas, R.C., Lima, J.R., Belfort, F.G., Lopes, P.R., Marins, J.C. "Pregame hydration status, sweat loss and fluid intake in elite Brazilian soccer male players during competition," Journal of Sports Sciences, 30 (1): 37-42, 2012.

[19] Roffey, D.M., Byrne, N.M., Hills, A.P. "Effect of stage duration on physiological variables commonly used to determine maximum aerobic performance during cycle ergometry," Journal of Sports Sciences, 25(12), 1325-35, 2007.

[20] Welsh, R.S., Davis, M.J., Burke, J.R., Williams, H.G. "Carbohydrates and physical/mental capacity during intermittent exercise to fatigue," Medicine and Science in Sports and Exercise, 34, 723-731, 2002.

[21] Nicholas, C.W., Williams, C., Lakomy, H.K., Phillips, G., Nowitz, A. "Influence of ingesting a carbohydrate-electrolyte solution on endurance capacity during intermittent, high-intensity shuttle running,” Journal of Sports Sciences, 13, 283-290, 1995.

[22] Jones, A.M., Doust, J.H. "A 1\% treadmill grade most accurately reflects the energetic cost of outdoor running," Journal of Sports Sciences. 14(4), 321-327. 1996.

[23] Potgieter, S. "Sport nutrition: a review of the latest guidelines for exercise and sport nutrition from the American College of Sport Nutrition, the International Olympic Committee and the International Society for Sports Nutrition,” South African Journal of Clinical Nutrition, 26 (1), 6-16, 2013.

[24] Rodriguez, N.R., DiMarco, N.M., Langley, S. "Nutrition for athletic performance. Joint position statement of the American College of Sports Medicine, the American Dietetic Association and the Dieticians of Canada," Medicine and Science in Sports and Exercise, 44(3): 709-731, 2009.

[25] Dill, D., Costill, D.L. "Calculation of percentage changes in volumes of blood, plasma, and red cells in dehydration," Journal of Applied Physiology, 37, 247-248, 1974.

[26] Minehan, M.R., Riley, M.D., Burke, L.M. "Effect of flavour and awareness of kilojoule content of drinks on preference," International Journal of Sport Nutrition and Exercise Metabolism, 12 (2002): 81-92. 
[27] Fallowfield, J.L., Williams, C., Booth, J., Choo, B.H., Growns, S "Effect of water ingestion on endurance capacity during prolonged running," Journal of Sports Sciences, 14, 497-502, 1996.

[28] Hargreaves, M., Dillom P., Angusm D., Febbraio, M. "Effect of fluid ingestion on muscle metabolism during prolonged exercise," Journal of Applied Physiology, 80, 363-366, 1996.

[29] Coombes, J., Hamilton, K. "The effectiveness of commercially available sports drinks," Sports Medicine, 29, 181-209, 2000.

[30] Currell, K., Jeukendrup, A. "Superior performance with ingestion of multiple transportable carbohydrates," Medicine and Science in Sports and Exercise, 40, 275-281, 2008.

[31] Davis, J.M., Welsh, R.S., De Volve, K.L., Anderson, N.A "Effects of branched chain amino acids and carbohydrate on fatigue during intermittent, high intensity exercise," International Journal of Sports Medicine, 20, 419-428, 1999.

[32] Passe, D., Horn, M., Murray, R. "Impact of beverage acceptability on fluid intake during exercise," Appetite, 35, 219-229, 2000.
[33] Montain, S., Coyle, E.F. "Influence of graded dehydration on hyperthermia and cardiovascular drift during exercise," Journal of Applied Physiology, 73, 1340-1350, 1992.

[34] Walsh, R.M., Noakes, T.D., Hawley, J.A., Dennis, S.C. "Impaired high-intensity cycling capacity time at low levels of dehydration," International Journal of Sports Medicine, 15, 392-398, 1994.

[35] Leiper, J., Broad, N., Maughan, R. "Effect of intermittent highintensity exercise on gastric emptying in man," Medicine and Science in Sports and Exercise, 33 (8), 1270-1278, 2001.

[36] Maughan RJ, Shirreffs SM, Leiper JB. Errors in the estimation of hydration status from changes in body mass. Journal of Sports Sciences, 25 (7), 797-804, 2007.

[37] Costill, D.L., Fink, W. "Plasma volume changes following exercise and thermal dehydration," Journal of Applied Physiology, 37, 521-26, 1974.

[38] Russell M, Benton D, Kingsley M. Influence of carbohydrate supplementation on skill performance during a soccer match simulation. Journal of Science and Medicine in Sport, 15, 348-354, 2012. 